\title{
Histamine lontophoresis as in vivo Model to Study Human Skin Inflammation with Minimal Barrier Impairment: Pilot Study Results of Application of the Model to a Sensitive Skin Panel
}

\author{
Denise Falcone $^{a} \quad$ Natallia Uzunbajakavab Renée Richters ${ }^{a}$ \\ Peter C.M. van de Kerkhof ${ }^{a}$ Piet E.J. van Erp ${ }^{a}$ \\ a Department of Dermatology, Radboud University Medical Center, Nijmegen, and ${ }^{\mathrm{b}}$ Philips Research, \\ Eindhoven, The Netherlands
}

\section{Keywords}

Histamine - lontophoresis - Biophysical measurements · Immunohistochemistry · Histology · Image analysis ·

Skin barrier - In vivo model of cutaneous inflammation . Sensitive skin

\begin{abstract}
Background/Aims: Histamine iontophoresis is known to elicit itch and a wheal-and-flare reaction; however, its impact on the skin barrier and underlying compartments has not been thoroughly evaluated yet. The primary objective of this study was to characterize that using immunohistochemistry, biophysical measurements, and image analysis, and secondly, to explore whether skin reactions to this model differ in sensitive skin (SS). Methods: Eighteen healthy subjects, $n=$ 9 with SS and $n=9$ with non-sensitive skin (NSS), were included based on a perception-based questionnaire. Histamine iontophoresis was performed on the buttock, and skin reactions were evaluated up to $72 \mathrm{~h}$ after stimulation. $\boldsymbol{R e}$ sults: The wheal-and-flare peaked at $30 \mathrm{~min}$; after $8 \mathrm{~h}$, no clinical signs were visible. No signs of disruption of the stratum corneum, as well as no increase in the number of
\end{abstract}

\section{KARGER}

(C) 2017 S. Karger AG, Basel

E-Mail karger@karger.com

www.karger.com/spp
Ki67-positive cells emerged, whereas fewer tryptase-positive mast cells and increased epidermal thickness were observed at 1 and $72 \mathrm{~h}$, respectively. SS subjects showed higher perception of itch compared to NSS subjects. Conclusion: Histamine iontophoresis is a well-standardized in vivo model to quantitatively study the early stages of cutaneous inflammation with minimal impact on the skin barrier. In line with previous studies, it highlighted increased sensory perceptions in SS.

(c) 2017 S. Karger AG, Basel

\section{Introduction}

The barrier function of the skin is fulfilled primarily by the stratum corneum (SC), the outermost layer of the epidermis [1]. The integrity of the SC as skin barrier depends on the interplay of several factors, including the process of proliferation of keratinocytes from the basal layer and their gradual differentiation to corneocytes across the epidermis. Upon disruption of the SC, the release of mediators from keratinocytes, including several interleukins and chemokines [2], prompts the onset of an inflamma-

Denise Falcone, MSc

Radboud University Medical Cente René Descartesdreef 1, PO Box 9101, Internal postal code 370 NL-6500 HB Nijmegen (The Netherlands)

E-Mail denise.falcone@ radboudumc.nl 
tory response, resulting in a transient infiltrate of immune cells in the dermis, and hyperproliferation and abnormal differentiation in the epidermis [3].

In order to study the cutaneous inflammatory response in vivo, human skin models can be used. These models consist in the application of minimally invasive and standardized challenges to the skin, followed by evaluation of skin reactions at one or several points in time. Examples include tape stripping, consisting in repeated application of adhesive tape to mimic disruption of the skin barrier in disease or following skin-material interactions $[3,4]$, and application of leukotriene $\mathrm{B}_{4}$ to mimic psoriasis-like infiltration of immune cells in the epidermis [5]. In this study, we focus on one such in vivo model: histamine iontophoresis. Histamine, either exogenously applied or endogenously released from mast cells, is known to elicit a triple response $[6,7]$ : itch, because of excitation of mechanoinsensitive $C$ fibers [8]; wheal, due to increased capillary permeability; and flare, induced by the release of vasoactive neuropeptides from afferent nerve fibers [7]. Iontophoresis is based on the use of a small and defined electric current to facilitate the transport of ionized molecules across the skin barrier $[9,10]$. In addition, albeit it cannot entirely avoid passive diffusion and variability thereof, iontophoresis is less influenced by the condition of the skin at the application site than topically applied molecules on the SC [10]. Histamine iontophoresis has been widely used as experimental itch model both in healthy and diseased states $[6,7,11-$ 13] and has been described as a quantifiable model for the study of the early stages of cutaneous inflammation [14]. However, to our best knowledge, no study thoroughly evaluated the effect of this model on the epidermal and dermal compartments.

The primary objective of this study was to characterize the effects of histamine iontophoresis on the epidermal and dermal compartments using immunohistochemistry and noninvasive assessments including biophysical methods and image analysis. In this respect, we propose an easy-to-use method to segment the wheal-and-flare reaction using classical image-processing techniques. We investigated in particular the impact on the skin barrier, the underlying hypothesis being that histamine iontophoresis exerts its effects primarily on the dermal vasculature and cutaneous sensory system and can thus be used as a model of acute and local skin inflammation with minimal barrier impairment, in contrast with other in vivo models such as tape stripping and application of leukotriene $\mathrm{B}_{4}$.

Skin Responses to Histamine
As a secondary objective, we explored whether skin responses to histamine iontophoresis differ significantly between subjects with sensitive skin (SS) and nonsensitive skin (NSS). With as much as $50-61 \%$ women and $30-44 \%$ men reporting SS in the industrialized world, and consensus on the definition and pathomechanism remaining elusive despite extensive research [15], SS has been identified as a global challenge [16]. However, recent clinical studies, based on the selection of a SS and NSS panel according to a novel perception-based questionnaire [17] and on the application of in vivo skin models followed by clinical, biophysical, and immunohistochemical analysis, have shown that aberrant vascular and inflammatory reactions, accompanied by enhanced sensory reactivity, were the hallmarks of SS [18-20]. We thus hypothesized that the triple response elicited by histamine iontophoresis might differ between SS and NSS subjects. In addition, since histamine has been reported to be normally excluded by the skin unless the barrier is compromised $[6,21]$, topical application of histamine was added to evaluate whether stronger reactions possibly observed in SS subjects might be due to aberrant properties of the SC [15].

\section{Materials and Methods}

\section{Study Participants}

Potential participants were recruited via websites and asked to fill the novel perception-based questionnaire [17], as previously described [18-20]. Briefly, inclusion was based on self-assessed skin sensitivity and on a sensitive skin score obtained by rating skin perceptions (i.e., discomfort, stinging, redness, dryness) following exogenous and endogenous triggers (i.e., toiletries, shaving, heat, cold, clothes, emotions). The score was compared to upper and lower quartiles previously determined [17]. If the score was above the upper quartile and the subject reported slightly higher or much higher SS values compared to others, he/she was included in the group with SS. If the score was below the lower quartile and the subject reported equal or lower skin sensitivity compared to others, he/she was included in the group with NSS. Additional criteria for inclusion were Fitzpatrick skin type II or III and willingness to give a written informed consent. Pregnant or breastfeeding women and volunteers with a history of skin diseases, atopic or allergic predisposition (i.e., atopic dermatitis, asthma, allergic rhinoconjunctivitis), use of immunosuppressive drugs, compromised skin at the experimental sites (volar forearm and lower back) and presence of implanted electrical devices (e.g. cardiac pacemakers) were excluded from participation. Volunteers were asked not to apply toiletries on the experimental sites from $24 \mathrm{~h}$ before the experiments and not to sunbathe or use a tanning bed from 2 weeks before the experiments. The study was performed in a temperature- and humidity-controlled room at the dermatology department of Radboud University Medical Center, Nijmegen, The Netherlands, between April and Novem-

Skin Pharmacol Physiol 2017;30:246-259

DOI: $10.1159 / 000477416$ 
ber 2015 and was approved by the ethics committee Regio Arnhem-Nijmegen. Before the start of the study procedures, the volunteers were left to acclimatize for $15 \mathrm{~min}$ with the body sites to be assessed uncovered.

\section{Randomization}

All subjects underwent the same study procedures up to $60 \mathrm{~min}$ after histamine iontophoresis with respect to the noninvasive measurements, whereas they underwent a randomization with respect to the skin biopsies taken at $1,8,24$, and $72 \mathrm{~h}$ after histamine iontophoresis: namely, 2 biopsies at 2 out of the 4 possible time points were taken from each volunteer. This design was a compromise between getting insights into skin reactions to histamine iontophoresis at the immunohistochemical level and reducing the burden of the study for the volunteers. The choice of the time points was based on previous studies [18-20].

\section{Histamine Iontophoresis}

Histamine iontophoresis was performed on the buttock (at the level of the upper side of the intergluteal cleft) at $0.4 \mathrm{~mA}$ for 2.5 min using an iontophoresis system (Chattanooga Group, Hixson, TN, USA) and a pair of silver-silver chloride electrodes with an active area of $7.2 \mathrm{~cm}^{2}$ (Iomed Iogel Iontophoresis Electrode small; Chattanooga Group, Hixson, TN, USA), as previously described $[11,12]$. This resulted in a current density of $0.06 \mathrm{~mA} /$ $\mathrm{cm}^{2}$. The active area was filled with $1.5 \mathrm{~mL}$ of a solution of $0.5 \%$ histamine dihydrochloride (Allergopharma BV, Zeist, The Netherlands) in $1 \%$ hypromellose gel prepared by the local pharmacy. The $\mathrm{pH}$ of the solution was 4.5-5.0. Prior to stimulation, the skin areas where the electrodes needed to be applied were gently rubbed with a $5 \times 5 \mathrm{~cm}$ tissue (Cutisoft, BSN Medical $\mathrm{GmbH}$, Hamburg, Germany) soaked in $1.5 \mathrm{~mL}$ distilled water in order to remove sebum and other impurities possibly causing localized increased resistance to the ionic flux. Every $15 \mathrm{~s}$ during iontophoretic histamine application, the subjects were asked to rate their level of perceived itch on a visual analog scale (VAS) ranging from 0 (no perception) to 10 (strongest possible itch perception), with 3 being the threshold for the willingness to scratch the skin [6]. The average itch score and the time to reach the scratching threshold were calculated. To avoid evaporative cooling, remaining amounts of gel were wiped off immediately after stimulation [14]. The level of perceived itch was asked also at 5, 30, and $60 \mathrm{~min}$ after histamine iontophoresis.

\section{Topical Application of Histamine}

Between 30 and 60 min after stimulation with histamine iontophoresis, the same amount of histamine $(1.5 \mathrm{~mL})$ was applied topically on the contralateral side of the buttock (10 cm apart) and, subsequently, on the nondominant mid volar forearm. Histamine was left on the skin for $2.5 \mathrm{~min}$ and wiped off immediately afterwards. The application area of $2 \times 3.5 \mathrm{~cm}$ was chosen to approximately match the area of the active electrode. Ratings of itch perception during topical histamine application and 5 min after wiping off [21] were performed as for histamine iontophoresis.

\section{Noninvasive Measurements}

Transepidermal water loss (TEWL) (Aquaflux AF200, Biox, London, UK) and skin redness (a* value) (Spectrophotometer 2600d, Konica Minolta, Tokyo, Japan) were measured at baseline on the buttock and on the nondominant volar forearm, and at 5,
30, and $60 \mathrm{~min}$ after histamine iontophoresis. Depending on the randomization performed for skin biopsies, TEWL and a* value were measured on the buttock also at 8,24 , and $72 \mathrm{~h}$ after stimulation. Measurements were repeated 3 times on adjacent skin areas and averaged.

Skin photographs were taken at 5, 30, and 60 min after histamine iontophoresis with a single-lens reflex digital camera (D3200, Nikon, Japan), equipped with a 32-LED ring flash (PLMRFN, Polaroid, USA) to provide a shadow-free illumination. An algorithm, implemented in Matlab (The MathWorks Inc., Natick, MA, USA), was applied to the digital images to segment the wheal-and-flare reaction. Briefly, different combinations of histogram-based contrast enhancement and thresholding were tested and compared to manual erythema segmentation. The best combinations were found to be the linear histogram-based contrast enhancement followed by thresholding with the Isodata method [22] for the reaction at 5 and $30 \mathrm{~min}$, and the nonlinear histogram-based contrast enhancement with Isodata thresholding for the reaction at $60 \mathrm{~min}$. The acquisition setup and the algorithm are described in the online supplementary material (see www.karger.com/doi/10.1159/000477416 for all online suppl. material).

\section{Tissue Processing and Immunohistochemistry}

Prior to the biopsy procedure, the skin was cleansed with chlorhexidine $0.5 \% \mathrm{~m} / \mathrm{v}$ in alcohol $70 \% \mathrm{v} / \mathrm{v}$. Punch biopsies $(3 \mathrm{~mm})$ were taken under $1 \%$ lidocaine chloride. The specific choice of the anesthetic not containing adrenalin as a vasoconstrictor was made not to counteract the vasodilating effect of histamine. One additional biopsy was taken from nonchallenged skin serving as an internal control. In total, 3 biopsies were taken from each volunteer. All specimens were fixed in $10 \%$ formalin for subsequent paraffin embedding and sectioned at $6 \mu \mathrm{m}$ thickness. Paraffin-embedded specimens were deparaffinized in Histosafe (Adamas Instrumenten BV, The Netherlands) and rehydrated in decreasing concentrations of alcohol (100-50\%) and demineralized water. For K16 and filaggrin, xylene (Klinipath BV, The Netherlands) was used for deparaffinization. Antigen retrieval was achieved by citrate buffer ( $\mathrm{pH} 6.0,10 \mathrm{~min}$ at $100^{\circ} \mathrm{C}$ ) for Ki67, CD1a, CD31, K16 and filaggrin stainings, and by EDTA/Tween-20 $\left(10 \mathrm{~mm}\right.$ EDTA + 0.05\% Tween-20, $\left.\mathrm{pH} \mathrm{8.0,10} \mathrm{min} \mathrm{at} 100^{\circ} \mathrm{C}\right)$ for the $\mathrm{CD} 3$ staining. The tryptase antibody did not require antibody retrieval steps. Endogenous peroxidase activity was blocked by $3 \%$ $\mathrm{H}_{2} \mathrm{O}_{2}$ in methanol for Ki67, CD1a, CD31, CD3 and tryptase antibodies. This step was followed by preincubation in $1 \%$ bovine serum albumin (BSA) (Sanquin Reagents, The Netherlands) in phosphate-buffered saline (PBS) for $15 \mathrm{~min}$ for Ki67 and tryptase antibodies, $30 \mathrm{~min}$ for CD1a and CD3 antibodies and $60 \mathrm{~min}$ for CD31 antibody. For K16 and filaggrin, 5\% normal goat serum (Vector Laboratories Inc., USA) in PBS for 15 min was used. Incubation with primary antibodies dissolved in 1\% BSA was performed overnight at room temperature, except K16 and filaggrin which were incubated for $60 \mathrm{~min}$. The following clones and dilutions were used: Ki67 (1:100, clone MIB-1, Dako), tryptase (1:100,000, clone AA1, Dako), CD1a (1:200, clone 010, Dako), CD3 (1:100, clone F7.2.38, Abcam), CD31 (1:80, clone JC70A, Dako), K16 (1:50, clone LL025, Biotrend), filaggrin (1:100, polyclonal 19058, BioLegend). For all stainings except K16 and filaggrin, amplification was obtained by EnVision anti-mouse (Dako, Glostrup, Denmark) for $45 \mathrm{~min}$, visualization of the antibody with $3,3^{\prime}$-diaminobenzidine
Falcone/Uzunbajakava/Richters/ van de Kerkhof/van Erp 
Table 1. Overview (number of patients) of study procedures and measurements including randomization performed for taking skin biopsies at 1,8,24, and $72 \mathrm{~h}$ after histamine iontophoresis on the buttock

\begin{tabular}{|c|c|c|c|c|c|c|c|c|}
\hline & Baseline & $\begin{array}{l}\text { During } \\
\text { iontophoresis }\end{array}$ & $5 \min$ & $30 \mathrm{~min}$ & $1 \mathrm{~h}$ & $8 \mathrm{~h}$ & $24 \mathrm{~h}$ & $72 \mathrm{~h}$ \\
\hline \multicolumn{9}{|l|}{ TEWL } \\
\hline SS & 9 & - & 9 & 9 & 9 & 4 & 4 & 4 \\
\hline NSS & 9 & - & 9 & 9 & 9 & 4 & 4 & 4 \\
\hline \multicolumn{9}{|l|}{$\mathrm{a}^{*}$ value } \\
\hline SS & 9 & - & 9 & 9 & 9 & 4 & 4 & 4 \\
\hline NSS & 9 & - & 9 & 9 & 9 & 4 & 4 & 4 \\
\hline \multicolumn{9}{|c|}{ VAS score for itch } \\
\hline SS & 9 & 9 & 9 & 9 & 9 & - & - & - \\
\hline NSS & 9 & 9 & 9 & 9 & 9 & - & - & - \\
\hline \multicolumn{9}{|c|}{ Skin photograph } \\
\hline SS & - & - & 9 & 9 & 9 & - & - & - \\
\hline NSS & - & - & 9 & 9 & 9 & - & - & - \\
\hline \multicolumn{9}{|c|}{ Skin biopsy } \\
\hline SS & $9^{1}$ & - & - & - & $6^{1}$ & $4^{1}$ & 4 & 4 \\
\hline NSS & $9^{1}$ & - & - & - & $6^{1}$ & 4 & 4 & $4^{1}$ \\
\hline
\end{tabular}

NSS, nonsensitive skin; SS, sensitive skin; TEWL, transepidermal water loss; VAS, visual analog scale. ${ }^{1}$ Biopsies taken from 1 volunteer with SS at baseline, at 1 and at $8 \mathrm{~h}$, as well as biopsies taken from 1 volunteer with NSS at baseline, at 1 and at $72 \mathrm{~h}$ could not be evaluated due to damage.

tetrahydrochloride solution (Sigma-Aldrich, St. Louis, MO, USA) for $10 \mathrm{~min}$ and counterstaining with Mayer's hematoxylin (SigmaAldrich, St. Louis, MO, USA). Lastly, specimens were dehydrated in increasing concentrations of alcohol (50-100\%) and Histosafe, and mounted using Permount glue (Thermo Fisher Scientific, Waltham, USA). For K16 and filaggrin, visualization of the antibody was obtained with Alexa Fluor 488 conjugate $(1: 200)$ and Alexa Fluor 647 conjugate (1:200) (Invitrogen, USA) in 1\% BSA. Counterstaining and mounting were obtained with Fluoromont-G with diamidine phenylindole (eBioscience, USA).

\section{Semiquantitative Assessment of Immunohistochemical}

Markers

Specimens were imaged using an Axiokop 2 MOT microscope at a magnification of $\times 200$, an Axiocam MRc5 digital camera and AxioVision software rel. 4.8 (Carl Zeiss, Germany). Semiquantitative analysis of immunohistochemical markers was performed using macrocolor deconvolution and color thresholding in ImageJ (version 1.49, National Institutes of Health, USA). The thickness of the SC and of the viable epidermis were measured in hematoxylin-eosin (HE)-stained sections by dividing the SC/viable epidermis area by the average length of the basal membrane (BM) (computed as Feret's distance in ImageJ) [18-20]. Ki67-positive cells were expressed as number of cells per millimeter BM length. CD1a-positive cells were measured as percentage of the viable epidermal surface where a positive signal was detected. The dermis was assessed from the BM down to $350 \mu \mathrm{m}$ across the specimen. Tryptase-positive cells were expressed as number of cells per square millimeter dermis. CD31- and CD3-positive cells were expressed as percentage of the dermal surface where a positive signal was detected.

Skin Responses to Histamine
Immunofluorescence images of K16 and filaggrin were obtained using an Axio Imager M2 microscope at a magnification of $\times 200$, an AxioCam 503 Mono digital camera and ZEN 2 pro software rel. 5.8 (Carl Zeiss, Germany) and qualitatively compared.

\section{Statistical Analysis}

Results are presented as median (minimum - maximum). To answer the primary objective of the study, differences between values of the same variable measured at baseline and after stimulation with histamine iontophoresis were analyzed with the Wilcoxon signed rank test for nonparametric repeated measures. Of note, for the immunohistochemical markers measured at $1,8,24$, and $72 \mathrm{~h}$ and for TEWL and $\mathrm{a}^{*}$ value measured at 8,24 , and $72 \mathrm{~h}$ following histamine iontophoresis, a paired comparison with baseline values was performed, i.e., baseline values from volunteers sampled at other time points were not pooled together. To answer the secondary objective of the study, differences between SS and NSS subjects were analyzed at baseline and at 5, 30, and $60 \mathrm{~min}$ after histamine iontophoresis using the Mann-Whitney exact test for nonparametric independent values. In the comparison between SS and NSS subjects, the following variables were considered: TEWL, a* value, wheal-and-flare area, average VAS score for itch during histamine iontophoresis and topical histamine application, and time to reach the scratching threshold during histamine iontophoresis. Correlations were done with the Spearman rho. Statistical analyses were performed with SPSS Statistics (v. 20, IBM SPSS Inc., USA). A $p$ value $\leq 0.05$ was considered statistically significant. Due to the exploratory nature of this study, no corrections for multiple comparisons were applied. 
Fig. 1. Representative photographs of skin reactions to histamine iontophoresis in 2 volunteers ( $\mathbf{a}-\mathbf{c}$ and $\mathbf{d}-\mathbf{f}$ ). $\mathbf{a}, \mathbf{d}$ At $5 \mathrm{~min}$, early onset of edema and erythema at the stimulated site and of flare in the surrounding skin were observed. b, e At $30 \mathrm{~min}$, edema increased while the flare reaction was mostly unchanged. c, f At $60 \mathrm{~min}$, the edema and the surrounding flare reaction generally decreased, and in most volunteers an irregularly dotted erythema pattern appeared in correspondence of the wheal.
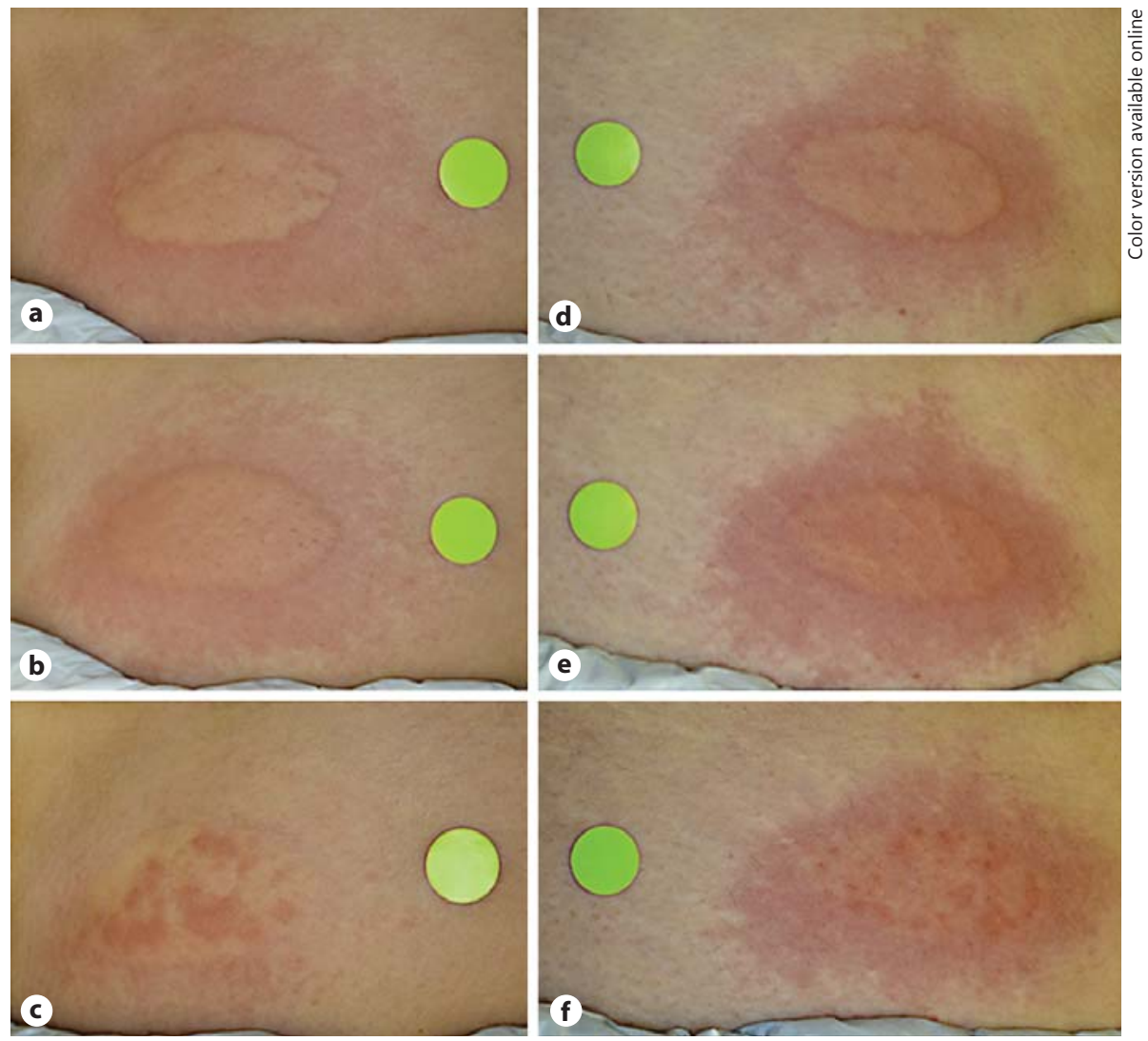

\section{Results}

\section{Study Population}

A total of 106 potential participants received the questionnaire. Fifty questionnaires were returned and, of these, 32 had to be excluded because of the score being outside the proper range or because of concomitant presence of skin diseases, atopic or allergic predisposition. In total, 18 subjects were eligible for inclusion in the study, $n=9$ with SS ( 1 male, 8 females) and $n=9$ with NSS (2 males, 7 females). In both groups, the median age was 21 years (19-36 in the SS group, 20-32 in the NSS group) and, in both groups, 3 subjects had Fitzpatrick skin type II and 6 subjects had Fitzpatrick skin type III. The number of subjects measured at each time point is described in Table 1.

\section{Histamine Iontophoresis: Clinical Assessment and \\ Noninvasive Measurements}

Representative wheal-and-flare reactions at 5, 30 and 60 min after histamine iontophoresis are shown in Figure 1. At 8,24 , and $72 \mathrm{~h}$, no wheal or flare was any longer visible in skin photographs.
The values of TEWL, $a^{*}$ value and wheal-and-flare area measured at baseline and at 5, 30, and 60 min after histamine iontophoresis are shown in Figure 2. In both SS and NSS subjects, TEWL increased by approximately $3.5 \mathrm{~g} / \mathrm{m}^{2} / \mathrm{h}$ at $5 \mathrm{~min}$ and started to recover at $30 \mathrm{~min}$, yet at $60 \mathrm{~min}$ it remained slightly but significantly higher than baseline $(p \leq 0.05)$. In both SS and NSS subjects, the $\mathrm{a}^{*}$ value increased by approximately $6 \mathrm{AU}$ at $5 \mathrm{~min}$ and remained significantly higher than baseline up to $60 \mathrm{~min}$ $(p \leq 0.05)$. Similarly, in both SS and NSS subjects, the wheal-and-flare area at $30 \mathrm{~min}$ was generally comparable to the area at $5 \mathrm{~min}$, whereas it decreased at $60 \mathrm{~min}$. No differences between SS and NSS subjects emerged for either TEWL, $\mathrm{a}^{*}$ value or the wheal-and-flare area. Of note, there was no correlation between the $\mathrm{a}^{*}$ value and the wheal-and-flare area measured at 5 and $30 \mathrm{~min}$, whereas a weak yet significant correlation was present at $60 \mathrm{~min}$ $(\rho=0.512, p=0.030, n=18)$. The numerical data are reported in Table 2.

At 8,24 , and $72 \mathrm{~h}$, considering both groups together, no differences with respect to baseline were present for TEWL, while the $\mathrm{a}^{*}$ value was slightly higher at 24 and 
Fig. 2. The values of TEWL (a), a* value (b), wheal-and-flare area (c), and average VAS score for itch (d) measured at baseline and after histamine iontophoresis in volunteers with SS $(n=9)$ and NSS $(n=9)$. Values at baseline and up to $60 \mathrm{~min}$ after histamine iontophoresis were measured in all volunteers $(n=18)$. Values at 8,24 , and $72 \mathrm{~h}$ were measured in a subgroup of volunteers according to the randomization described in the Materials and Methods. Graphs represent medians and ranges (minimum-maximum).

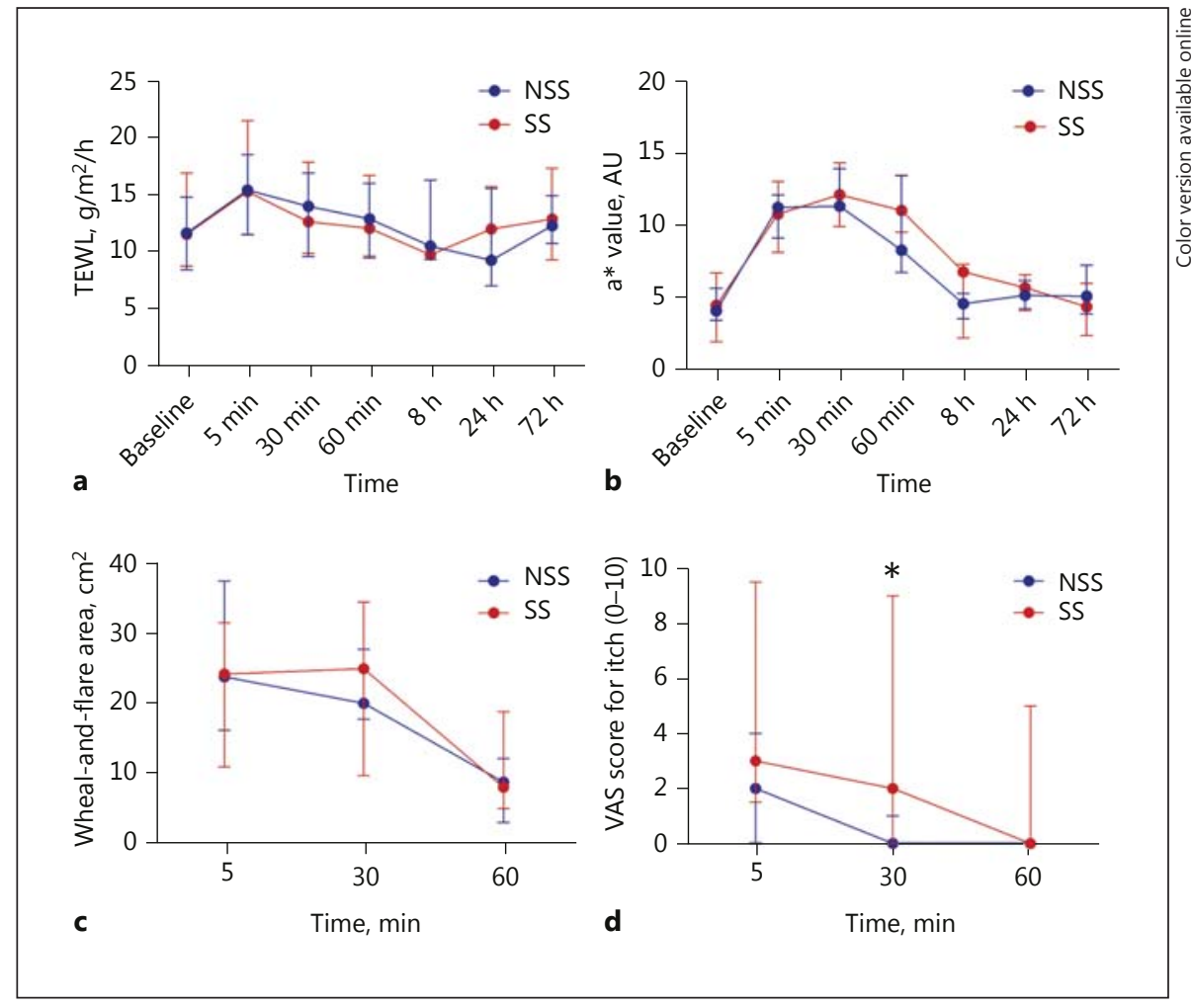

Table 2. Noninvasive assessments and VAS score for itch measured at baseline and at 5, 30, and 60 min after histamine iontophoresis ( $n=18 ; n=9$ with SS, $n=9$ with NSS)

\begin{tabular}{|c|c|c|c|c|c|c|c|c|c|c|c|c|}
\hline & \multicolumn{3}{|c|}{ Baseline } & \multicolumn{3}{|l|}{$5 \min$} & \multicolumn{3}{|c|}{$30 \mathrm{~min}$} & \multicolumn{3}{|c|}{$60 \mathrm{~min}$} \\
\hline & med. & range & $p$ value & med. & range & $p$ value & med. & range & $p$ value & med. & range & $p$ value \\
\hline \multicolumn{13}{|c|}{ TEWL, $\mathrm{g} / \mathrm{m}^{2} / \mathrm{h}$} \\
\hline SS & 11.5 & $8.7-16.8$ & \multirow[t]{2}{*}{ ns } & 15.2 & $11.4-21.5$ & \multirow[t]{2}{*}{ ns } & 12.6 & $9.8-17.8$ & \multirow[t]{2}{*}{ ns } & 12.0 & $9.6-16.6$ & \multirow[t]{2}{*}{ ns } \\
\hline NSS & 11.6 & $8.3-14.7$ & & 15.4 & $11.5-18.5$ & & 13.9 & $9.5-16.9$ & & 12.8 & $9.4-16.0$ & \\
\hline \multicolumn{13}{|c|}{$\mathrm{a}^{*}$ value, $\mathrm{AU}$} \\
\hline SS & 4.4 & $1.9-6.7$ & \multirow[t]{2}{*}{ ns } & 10.8 & $8.1-13.0$ & \multirow[t]{2}{*}{ ns } & 12.1 & $9.9-14.3$ & \multirow[t]{2}{*}{ ns } & 11.0 & $9.5-13.4$ & \multirow[t]{2}{*}{ ns } \\
\hline NSS & 4.0 & $3.4-5.6$ & & 11.2 & $9.1-12.1$ & & 11.3 & $11.0-13.9$ & & 8.2 & $6.7-13.4$ & \\
\hline \multicolumn{13}{|c|}{ Wheal-and-flare area, $\mathrm{cm}^{2}$} \\
\hline SS & 0.0 & 0.0 & \multirow[t]{2}{*}{ na } & 24.2 & $10.8-31.5$ & \multirow[t]{2}{*}{ ns } & 24.9 & $10.0-34.5$ & \multirow[t]{2}{*}{ ns } & 7.9 & $4.8-18.7$ & \multirow[t]{2}{*}{ ns } \\
\hline NSS & 0.0 & 0.0 & & 23.8 & $16.0-31.1$ & & 20.0 & $17.6-27.7$ & & 8.6 & $2.8-12.0$ & \\
\hline \multicolumn{13}{|c|}{ VAS score for itch $(0-10)$} \\
\hline SS & 0.0 & 0.0 & \multirow[t]{2}{*}{ na } & 3.0 & $1.5-9.5$ & \multirow[t]{2}{*}{ ns } & 2.0 & $0.0-9.0$ & \multirow[t]{2}{*}{0.004} & 0.0 & $0.0-0.5$ & \multirow[t]{2}{*}{ ns } \\
\hline NSS & 0.0 & 0.0 & & 2.0 & $0.0-4.0$ & & 0.0 & $0.0-1.0$ & & 0.0 & $0.0-0.0$ & \\
\hline
\end{tabular}

AU, arbitrary units; med., median; na, nonapplicable; ns, nonsignificant; NSS, nonsensitive skin; SS, sensitive skin; TEWL, transepidermal water loss; VAS, visual analog scale. $p$ values obtained with Mann-Whitney exact test for nonparametric independent values. 
Table 3. Biophysical measurements and immunohistochemical markers measured at baseline and at 8,24 , and $72 \mathrm{~h}$ after histamine iontophoresis

\begin{tabular}{|c|c|c|c|c|c|c|c|c|c|c|}
\hline & \multicolumn{4}{|c|}{ All (randomized) } & \multicolumn{3}{|c|}{ SS } & \multicolumn{3}{|c|}{ NSS } \\
\hline & $n$ & med. & range & $p$ value & $n$ & med. & range & $n$ & med. & range \\
\hline \multicolumn{11}{|c|}{ Biophysical measurements } \\
\hline \multicolumn{11}{|c|}{ TEWL, $\mathrm{g} / \mathrm{m}^{2} / \mathrm{h}$} \\
\hline Baseline $8 \mathrm{~h}$ & 8 & 9.6 & $8.7-14.0$ & ns & 4 & 9.4 & $8.7-11.5$ & 4 & 10.3 & $8.8-14.0$ \\
\hline $8 \mathrm{~h}$ & 8 & 9.8 & $9.3-16.3$ & & 4 & 9.7 & $9.4-10.5$ & 4 & 10.4 & $9.3-16.3$ \\
\hline Baseline $24 \mathrm{~h}$ & 8 & 10.9 & $8.3-16.8$ & ns & 4 & 12.3 & $10.2-16.8$ & 4 & 9.8 & $8.3-13.0$ \\
\hline $24 \mathrm{~h}$ & 8 & 10.8 & $6.9-15.7$ & & 4 & 11.9 & $9.4-15.7$ & 4 & 9.2 & $6.9-15.5$ \\
\hline Baseline $72 \mathrm{~h}$ & 8 & 12.8 & $8.7-16.8$ & ns & 4 & 12.4 & $8.7-16.8$ & 4 & 13.5 & $11.6-14.7$ \\
\hline $72 \mathrm{~h}$ & 8 & 12.4 & $9.2-17.3$ & & 4 & 12.8 & $9.2-17.3$ & 4 & 12.2 & $10.7-14.9$ \\
\hline \multicolumn{11}{|l|}{$a^{*}$ value, $A U$} \\
\hline Baseline $8 \mathrm{~h}$ & 8 & 4.2 & $1.9-6.7$ & ns & 4 & 5.4 & $1.9-6.7$ & 4 & 4.0 & $3.5-5.3$ \\
\hline $8 \mathrm{~h}$ & 8 & 5.2 & $2.2-7.3$ & & 4 & 6.7 & $2.2-7.3$ & 4 & 4.5 & $3.5-5.2$ \\
\hline Baseline $24 \mathrm{~h}$ & 8 & 4.6 & $3.4-6.6$ & 0.078 & 4 & 4.9 & $3.6-6.6$ & 4 & 3.9 & $3.4-5.6$ \\
\hline $24 \mathrm{~h}$ & 8 & 5.5 & $4.0-6.5$ & & 4 & 5.6 & $4.0-6.5$ & 4 & 5.1 & $4.2-6.1$ \\
\hline Baseline $72 \mathrm{~h}$ & 8 & 4.2 & $1.9-5.6$ & 0.023 & 4 & 4.1 & $1.9-4.8$ & 4 & 4.7 & $4.0-5.6$ \\
\hline $72 \mathrm{~h}$ & 8 & 4.4 & $2.3-5.9$ & & 4 & 4.3 & $2.3-5.9$ & 4 & 5.0 & $3.8-7.2$ \\
\hline \multicolumn{11}{|l|}{ Epidermal markers } \\
\hline \multicolumn{11}{|l|}{ SC thickness, $\mu \mathrm{m}$} \\
\hline Baseline $1 \mathrm{~h}$ & 10 & 19.3 & $16.5-32.5$ & ns & 5 & 21.3 & $17.5-29.6$ & 5 & 17.3 & $16.5-32.5$ \\
\hline $1 \mathrm{~h}$ & 10 & 19.5 & $15.0-37.2$ & & 5 & 20.5 & $18.9-28.1$ & 5 & 18.6 & $15.0-37.2$ \\
\hline Baseline $8 \mathrm{~h}$ & 7 & 18.2 & $15.6-29.6$ & ns & 3 & 18.5 & $18.2-29.6$ & 4 & 16.9 & $15.6-20.1$ \\
\hline $8 \mathrm{~h}$ & 7 & 18.6 & $16.1-27.1$ & & 3 & 23.2 & $21.0-27.1$ & 4 & 18.0 & $16.1-18.6$ \\
\hline Baseline $24 \mathrm{~h}$ & 8 & 17.9 & $11.3-32.5$ & ns & 4 & 19.9 & $11.3-22.7$ & 4 & 16.4 & $14.0-32.5$ \\
\hline $24 \mathrm{~h}$ & 8 & 18.3 & $11.4-40.3$ & & 4 & 22.5 & $11.4-26.3$ & 4 & 16.1 & $15.7-40.3$ \\
\hline Baseline $72 \mathrm{~h}$ & 7 & 18.2 & $11.3-20.1$ & ns & 4 & 17.9 & $11.3-18.4$ & 3 & 20.1 & $14.0-20.1$ \\
\hline $72 \mathrm{~h}$ & 7 & 19.3 & $13.7-22.5$ & & 4 & 17.5 & $13.7-21.3$ & 3 & 20.4 & $16.3-22.5$ \\
\hline \multicolumn{11}{|c|}{ Epidermis thickness, $\mu \mathrm{m}$} \\
\hline Baseline $1 \mathrm{~h}$ & 10 & 64.3 & $58.8-78.1$ & 0.065 & 5 & 64.8 & $61.3-69.2$ & 5 & 63.0 & $58.8-78.1$ \\
\hline $1 \mathrm{~h}$ & 10 & 67.5 & $61.7-75.5$ & & 5 & 66.1 & $61.7-70.2$ & 5 & 69.6 & $64.8-75.5$ \\
\hline Baseline $8 \mathrm{~h}$ & 7 & 67.7 & $63.0-80.9$ & ns & 3 & 67.7 & $64.8-69.2$ & 4 & 71.1 & $63.0-80.9$ \\
\hline $8 \mathrm{~h}$ & 7 & 67.8 & $56.2-81.5$ & & 3 & 67.8 & $67.2-76.9$ & 4 & 73.4 & $56.2-81.5$ \\
\hline Baseline $24 \mathrm{~h}$ & 8 & 63.9 & $58.8-79.4$ & 0.055 & 4 & 65.7 & $61.3-79.4$ & 4 & 62.7 & $58.8-75.5$ \\
\hline $24 \mathrm{~h}$ & 8 & 70.4 & $65.7-82.9$ & & 4 & 71.3 & $65.7-72.8$ & 4 & 68.8 & $66.4-82.9$ \\
\hline Baseline $72 \mathrm{~h}$ & 7 & 69.2 & $65.0-80.9$ & 0.016 & 4 & 69.2 & $65.7-79.4$ & 3 & 75.5 & $65.0-80.9$ \\
\hline $72 \mathrm{~h}$ & 7 & 80.3 & $71.3-86.3$ & & 4 & 78.4 & $72.1-84.6$ & 3 & 80.3 & $71.3-86.3$ \\
\hline \multicolumn{11}{|c|}{ Ki67, cells/mm BM } \\
\hline Baseline $1 \mathrm{~h}$ & 10 & 40.8 & $23.5-50.0$ & ns & 5 & 44.0 & $23.5-50.0$ & 5 & 32.8 & $26.0-49.3$ \\
\hline $1 \mathrm{~h}$ & 10 & 30.7 & $23.8-52.8$ & & 5 & 38.6 & $26.6-52.8$ & 5 & 28.1 & $23.8-39.6$ \\
\hline Baseline $8 \mathrm{~h}$ & 7 & 39.7 & $23.5-59.9$ & ns & 3 & 28.6 & $23.5-29.8$ & 4 & 48.4 & $29.2-59.9$ \\
\hline $8 \mathrm{~h}$ & 7 & 47.8 & $28.8-50.1$ & & 3 & 47.8 & $46.0-50.1$ & 4 & 44.4 & $28.8-49.4$ \\
\hline Baseline $24 \mathrm{~h}$ & 8 & 46.7 & $27.8-50.3$ & ns & 4 & 47.0 & $28.6-50.0$ & 4 & 41.0 & $27.8-50.3$ \\
\hline $24 \mathrm{~h}$ & 8 & 43.9 & $22.4-53.3$ & & 4 & 43.3 & $34.3-53.3$ & 4 & 44.7 & $22.4-51.5$ \\
\hline Baseline $72 \mathrm{~h}$ & 7 & 39.7 & $26.0-59.9$ & ns & 4 & 43.1 & $37.6-50.0$ & 3 & 27.8 & $26.0-59.9$ \\
\hline $72 \mathrm{~h}$ & 7 & 39.9 & $33.4-85.3$ & & 4 & 57.1 & $33.7-85.3$ & 3 & 39.9 & $33.4-52.0$ \\
\hline \multicolumn{11}{|c|}{ CD1a, \% epidermis } \\
\hline Baseline $1 \mathrm{~h}$ & 10 & 4.4 & $3.2-6.3$ & ns & 5 & 3.6 & $3.2-5.4$ & 5 & 4.5 & $4.2-6.3$ \\
\hline $1 \mathrm{~h}$ & 10 & 4.1 & $3.2-6.9$ & & 5 & 3.9 & $3.2-6.9$ & 5 & 4.2 & $4.0-4.7$ \\
\hline Baseline $8 \mathrm{~h}$ & 7 & 4.4 & $3.0-6.6$ & ns & 3 & 3.6 & $3.0-5.7$ & 4 & 4.4 & $3.9-6.6$ \\
\hline $8 \mathrm{~h}$ & 7 & 4.6 & $2.6-7.0$ & & 3 & 3.6 & $3.5-6.1$ & 4 & 4.6 & $2.6-7.0$ \\
\hline Baseline $24 \mathrm{~h}$ & 8 & 4.5 & $3.2-5.7$ & ns & 4 & 3.9 & $3.2-5.7$ & 4 & 4.5 & $3.9-4.9$ \\
\hline $24 \mathrm{~h}$ & 8 & 4.7 & $2.6-5.5$ & & 4 & 5.0 & $3.1-5.5$ & 4 & 3.7 & $2.6-5.4$ \\
\hline Baseline $72 \mathrm{~h}$ & 7 & 4.9 & $3.0-6.6$ & ns & 4 & 4.5 & $3.0-5.4$ & 3 & 6.3 & $4.9-6.6$ \\
\hline $72 \mathrm{~h}$ & 7 & 4.9 & $1.9-6.0$ & & 4 & 4.3 & $1.9-4.9$ & 3 & 5.0 & $5.0-6.0$ \\
\hline
\end{tabular}


Table 3 (continued)

\begin{tabular}{|c|c|c|c|c|c|c|c|c|c|c|}
\hline & \multicolumn{4}{|c|}{ All (randomized) } & \multicolumn{3}{|c|}{ SS } & \multicolumn{3}{|c|}{ NSS } \\
\hline & $n$ & med. & range & $p$ value & $n$ & med. & range & $n$ & med. & range \\
\hline \multicolumn{11}{|l|}{ Dermal markers } \\
\hline \multicolumn{11}{|l|}{ CD3, \% dermis } \\
\hline Baseline $1 \mathrm{~h}$ & 10 & 0.2 & $0.1-0.8$ & ns & 5 & 0.6 & $0.1-0.8$ & 5 & 0.2 & $0.1-0.2$ \\
\hline $1 \mathrm{~h}$ & 10 & 0.2 & $0.1-0.5$ & & 5 & 0.3 & $0.2-0.5$ & 5 & 0.2 & $0.1-0.5$ \\
\hline Baseline $8 \mathrm{~h}$ & 7 & 0.3 & $0.1-0.5$ & ns & 3 & 0.4 & $0.3-0.5$ & 4 & 0.3 & $0.1-0.4$ \\
\hline $8 \mathrm{~h}$ & 7 & 0.2 & $0.1-0.7$ & & 3 & 0.2 & $0.1-0.3$ & 4 & 0.3 & $0.2-0.7$ \\
\hline Baseline $24 \mathrm{~h}$ & 8 & 0.2 & $0.1-0.7$ & ns & 4 & 0.3 & $0.1-0.7$ & 4 & 0.2 & $0.1-0.6$ \\
\hline $24 \mathrm{~h}$ & 8 & 0.4 & $0.1-1.0$ & & 4 & 0.4 & $0.3-0.5$ & 4 & 0.5 & $0.1-1.0$ \\
\hline Baseline $72 \mathrm{~h}$ & 7 & 0.3 & $0.2-0.8$ & ns & 4 & 0.3 & $0.2-0.8$ & 3 & 0.4 & $0.2-0.6$ \\
\hline $72 \mathrm{~h}$ & 7 & 0.5 & $0.2-0.6$ & & 4 & 0.4 & $0.2-0.5$ & 3 & 0.5 & $0.5-0.6$ \\
\hline \multicolumn{11}{|l|}{ CD31, \% dermis } \\
\hline Baseline $1 \mathrm{~h}$ & 10 & 1.0 & $0.4-1.9$ & ns & 5 & 1.2 & $0.7-1.9$ & 5 & 0.8 & $0.4-1.1$ \\
\hline $1 \mathrm{~h}$ & 10 & 1.0 & $0.8-1.8$ & & 5 & 1.1 & $0.9-1.8$ & 5 & 0.9 & $0.8-1.4$ \\
\hline Baseline $8 \mathrm{~h}$ & 7 & 1.2 & $0.4-1.7$ & ns & 3 & 1.2 & $1.2-1.7$ & 4 & 1.1 & $0.4-1.4$ \\
\hline $8 \mathrm{~h}$ & 7 & 0.8 & $0.7-1.4$ & & 3 & 1.1 & $0.8-1.4$ & 4 & 0.7 & $0.7-0.8$ \\
\hline Baseline $24 \mathrm{~h}$ & 8 & 1.2 & $0.5-1.7$ & ns & 4 & 1.1 & $0.7-1.7$ & 4 & 1.2 & $0.5-1.7$ \\
\hline $24 \mathrm{~h}$ & 8 & 1.0 & $0.6-1.4$ & & 4 & 1.2 & $0.8-1.4$ & 4 & 0.9 & $0.6-1.4$ \\
\hline Baseline $72 \mathrm{~h}$ & 7 & 1.2 & $0.8-1.9$ & ns & 4 & 1.1 & $0.9-1.9$ & 3 & 1.2 & $0.8-1.7$ \\
\hline $72 \mathrm{~h}$ & 7 & 1.0 & $0.6-1.5$ & & 4 & 1.1 & $0.6-1.4$ & 3 & 0.8 & $0.7-1.5$ \\
\hline \multicolumn{11}{|c|}{ Tryptase, cells $/ \mathrm{mm}^{2}$ dermis } \\
\hline Baseline $1 \mathrm{~h}$ & 10 & 117.0 & $79.7-129.4$ & 0.037 & 5 & 114.7 & $79.7-129.4$ & 5 & 118.4 & $85.8-126.1$ \\
\hline $1 \mathrm{~h}$ & 10 & 101.0 & $76.0-119.5$ & & 5 & 104.4 & $76.0-112.1$ & 5 & 98.0 & $79.1-119.5$ \\
\hline Baseline $8 \mathrm{~h}$ & 7 & 80.6 & $61.1-124.5$ & ns & 3 & 80.6 & $79.7-86.3$ & 4 & 96.9 & $61.1-124.5$ \\
\hline $8 \mathrm{~h}$ & 7 & 76.4 & $66.4-99.6$ & & 3 & 67.2 & $66.4-76.4$ & 4 & 90.6 & $66.9-99.6$ \\
\hline Baseline $24 \mathrm{~h}$ & 8 & 107.0 & $61.1-128.1$ & ns & 4 & 107.2 & $80.6-123.8$ & 4 & 112.1 & $61.1-128.1$ \\
\hline $24 \mathrm{~h}$ & 8 & 102.0 & $70.1-141.7$ & & 4 & 96.9 & $70.1-122.8$ & 4 & 114.6 & $74.5-141.7$ \\
\hline Baseline $72 \mathrm{~h}$ & 7 & 105.0 & $75.3-129.4$ & ns & 4 & 109.8 & $86.3-129.4$ & 3 & 85.8 & $75.3-128.1$ \\
\hline $72 \mathrm{~h}$ & 7 & 122.0 & $67.3-156.2$ & & 4 & 129.3 & $67.3-147.5$ & 3 & 84.0 & $71.4-156.2$ \\
\hline
\end{tabular}

BM, basement membrane; med., median; ns, nonsignificant; NSS, nonsensitive skin; SC, stratum corneum; SS, sensitive skin. $p$ values obtained with Wilcoxon signed rank test for nonparametric repeated measures.

$72 \mathrm{~h}(p=0.078$ and $p=0.023$, respectively). The numerical data are reported in Table 3.

\section{Histamine Iontophoresis: VAS Score for Itch}

The average VAS score for itch measured during stimulation and the time necessary to reach the scratching threshold were not different between the groups: average $\mathrm{VAS}_{\mathrm{SS}}=4.3(1.6-6.8)$, average $\mathrm{VAS}_{\mathrm{NSS}}=4.1$ (0.6-6.6), time to threshold SS $=30 \mathrm{~s}(0-120 \mathrm{~s})$, time to threshold ${ }_{\text {NSS }}=37.5 \mathrm{~s}(15-75 \mathrm{~s})$. One subject with NSS never perceived VAS scores higher than the scratching threshold.

At 5 min after histamine iontophoresis, all subjects except 1 NSS subject still reported some itch. At $30 \mathrm{~min}$, remaining perceptions were reported by 2 subjects with
NSS and 8 with SS. At $60 \mathrm{~min}$, this was the case only for 3 subjects with SS. Values are shown in Figure 2, and numerical data are reported in Table 2.

\section{Histamine Iontophoresis: Histological and Immunohistochemical Markers}

The HE staining revealed no effects of histamine iontophoresis on the SC in terms of change of thickness or presence of parakeratosis. On the other hand, the living epidermis showed a trend to increased thickness at 1 and $24 \mathrm{~h}$ after histamine iontophoresis $(p=0.065$ and $p=$ 0.055 , respectively) and was significantly thicker at $72 \mathrm{~h}$ $(p=0.016)$. No inflammatory infiltrates in the epidermis or dermis were observed. Representative HE images are shown in Figure 3. 

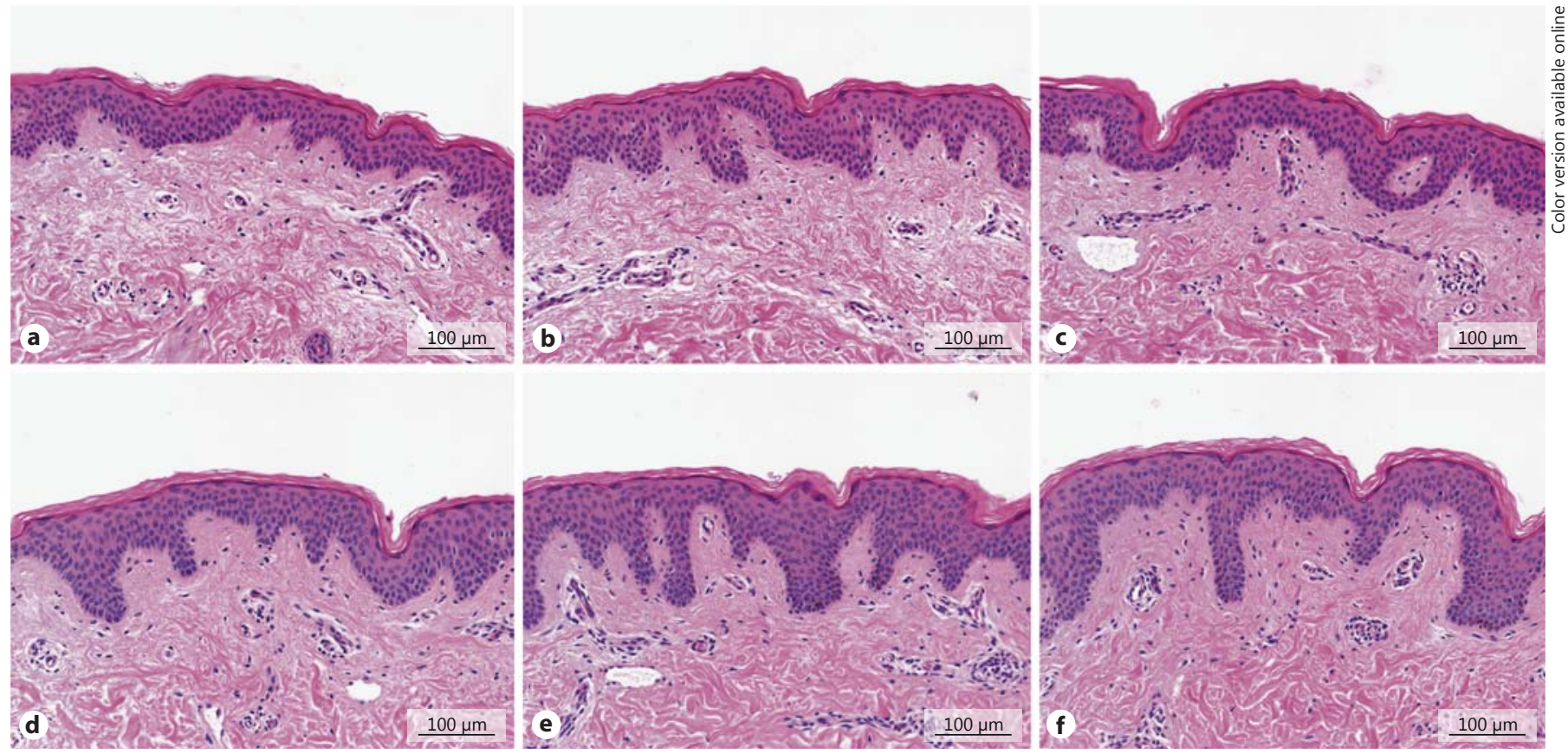

Fig. 3. Representative HE photographs of skin reactions to histamine iontophoresis in 2 volunteers (a-c and $\mathbf{d}-\mathbf{f})$. a, $\mathbf{d}$ Control skin. b At $1 \mathrm{~h}$, spongiosis is present in the epidermis. No changes in the stratum corneum are visible. c At $8 \mathrm{~h}$, no changes compared to control skin are visible. e, f At 24 and $72 \mathrm{~h}$, a slight increase in the epidermal thickness is visible. No atypia is observed, albeit the higher intercellular spaces in the upper stratum spinosum and in the stratum granulosum indicate spongiosis (more pronounced at $72 \mathrm{~h}$ ). No changes in the stratum corneum or influx of inflammatory infiltrates in either the epidermis or dermis are visible.
In the epidermal compartment, immunohistochemical stainings neither showed changes in the number of CD1a-positive cells nor in the number of Ki67-positive cells. Of note, a slight increase in the latter was present only in $2 \mathrm{SS}$ subjects at $72 \mathrm{~h}$. In the dermal compartment, no influx of CD3-positive cells or changes in the area covered by CD31-positive cells were visible. A significant decrease in the number of tryptase-positive mast cells was observed $1 \mathrm{~h}$ after histamine iontophoresis $(p=0.037)$. Representative images of the immonohistochemical stainings are shown in Figure 4, whereas the numerical data for each marker are reported in Table 3.

Qualitative assessment of the immunofluorescence staining revealed no presence of an increased expression of K16 at any time point, whereas a slight increase in the intensity of the filaggrin signal could be detected at 24 and $72 \mathrm{~h}$ in about half of the volunteers assessed at these time points. Representative images are shown in Figure 5.

\section{Topical Application of Histamine}

On the buttock, during topical histamine application, 5 subjects with NSS and 4 with SS did not perceive any sensation. The remaining volunteers had only transient and subthreshold perceptions, with no differences between SS and NSS subjects except 1 subject with SS who reported itch values above the scratching threshold: average $\mathrm{VAS}_{\mathrm{SS}}=0.5(0.0-4.1)$, average $\mathrm{VAS}_{\mathrm{NSS}}=0.0(0.0-0.8)$. At 5 min, 2 subjects with SS had remaining perceptions (VAS score of 1 and 5). One subject with NSS and 1 with SS developed a slight erythema, while edema was not visible in any volunteer.

On the nondominant mid volar forearm, baseline TEWL values were higher in subjects with SS: TEWL $L_{S S}=$ $12.0 \mathrm{~g} / \mathrm{m}^{2} / \mathrm{h}(8.6-16.9), \mathrm{TEWL}_{\mathrm{NSS}}=10.6 \mathrm{~g} / \mathrm{m}^{2} / \mathrm{h}(6.6-$ 14.3) $(p=0.031)$, whereas $\mathrm{a}^{*}$ values were not different: $\mathrm{a}^{*}$ value $_{S S}=6.2 \mathrm{AU}(3.1-8.3), \mathrm{a}^{*}$ value $_{\mathrm{NSS}}=6.2 \mathrm{AU}(3.4-8.1)$. During topical histamine application, 7 subjects with NSS and 4 with SS did not perceive any sensation. The remaining volunteers had only transient and subthreshold perceptions, with no differences between SS and NSS subjects except 1 subject with SS who reported itch values above the scratching threshold: average $\mathrm{VAS}_{\mathrm{SS}}=0.5(0.0-$ $4.6)$, average $\mathrm{VAS}_{\mathrm{NSS}}=0.0(0.0-0.5)(p=0.063)$. At $5 \mathrm{~min}$, 2 subjects with SS had remaining perceptions (VAS score of 2). One subject with SS developed a slight erythema, while edema was not visible in any volunteer. 

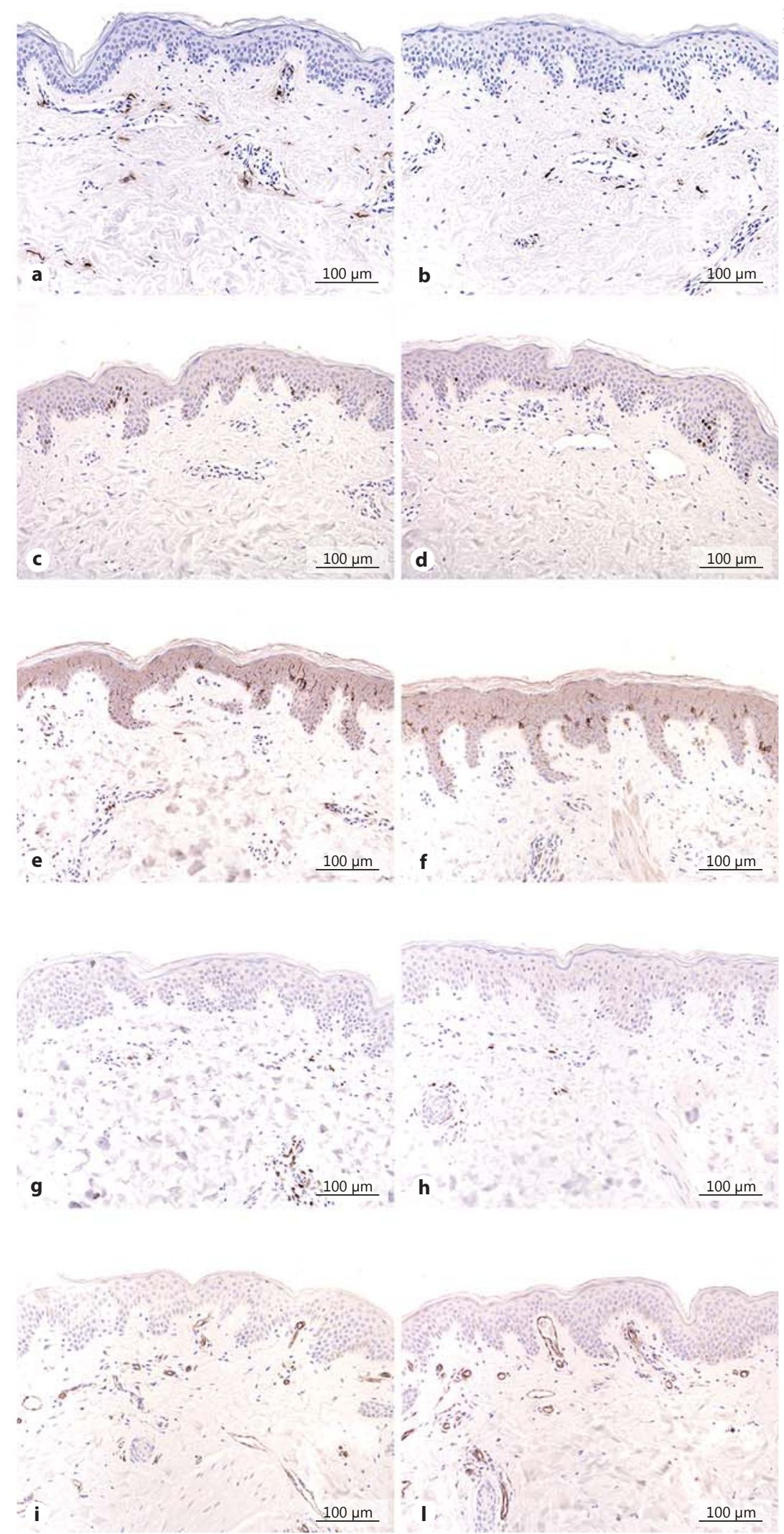

Fig. 4. Representative photographs of immunohistochemical data. a, b Tryptase-positive mast cells decreased significantly at $1 \mathrm{~h}$ after histamine iontophoresis (b) compared to control skin (a). Ki67-positive nuclei, CD1a-positive cells, CD3positive cells and CD31-positive cells showed no change at $72 \mathrm{~h}$ after histamine iontophoresis (d, f, $\mathbf{h}, \mathbf{I}$, respectively) compared to control skin (c, e, g, i, respectively).

Skin Responses to Histamine
Skin Pharmacol Physiol 2017;30:246-259 DOI: 10.1159/000477416 

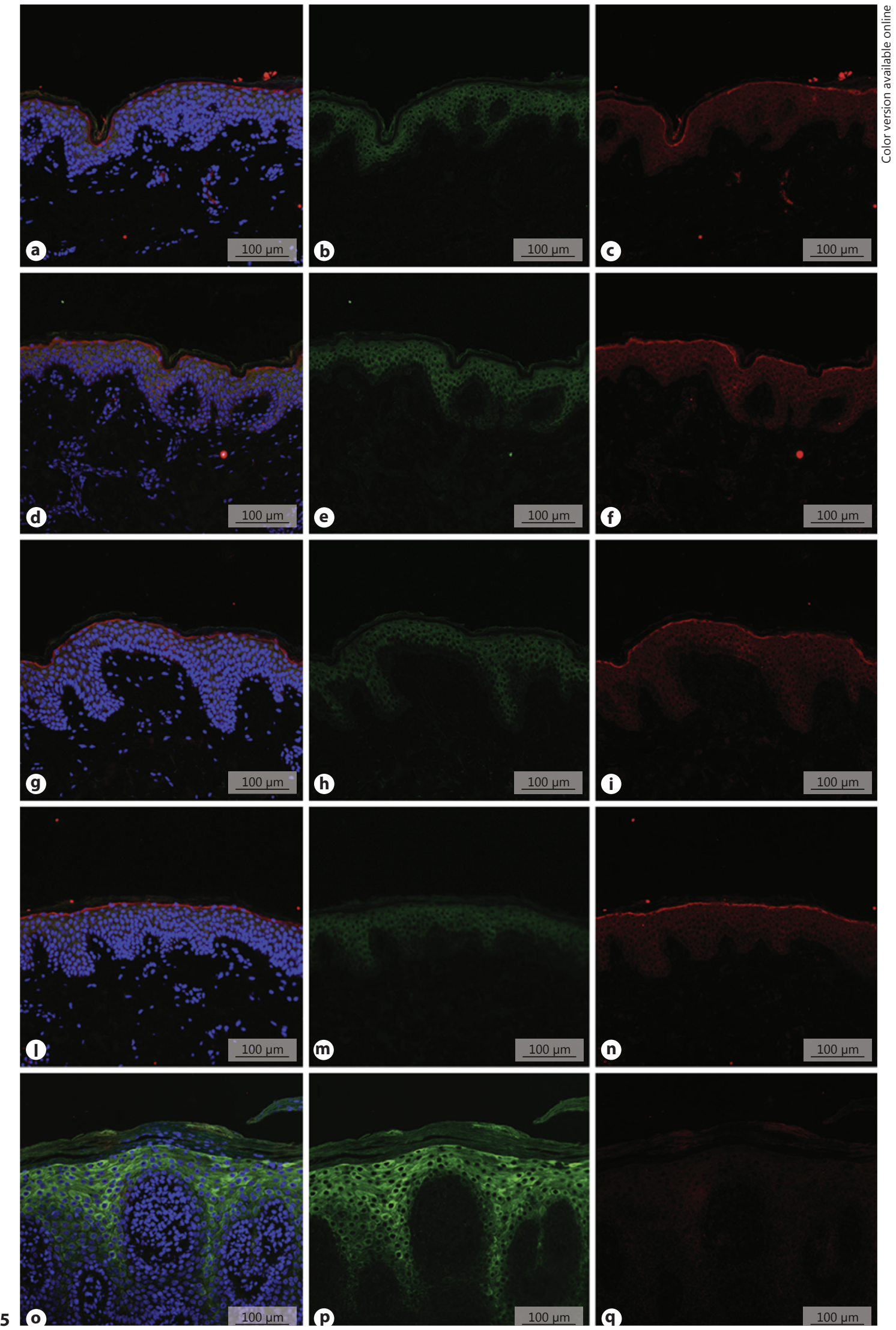

(For legend see next page.) 


\section{Discussion}

The primary objective of this study was to characterize the effects of histamine iontophoresis on the epidermal and dermal compartments combining invasive (immunohistochemistry) and noninvasive assessments.

We confirm that histamine iontophoresis is a quantifiable model for the study of the early stages of cutaneous inflammation [14], as indicated by the fast onset of the wheal-and-flare reaction at $5 \mathrm{~min}$. This acute reaction was mirrored by the presence of spongiosis in the epidermis (Fig. 3), possibly due to the underlying increased capillary permeability, and by the decrease in tryptase-positive mast cells, possibly indicative of degranulation induced by the vasoactive peptides released by histamine [23]. No clinical signs of irritation were visible at time points later than $1 \mathrm{~h}$. On the other hand, the lack of activation of Langerhans cells in the epidermis and of influx of $\mathrm{T}$ cells in the dermis, evidenced by the unchanged numbers of CD1a- and CD3-positive cells, respectively, confirms that this model (at least with the parameters chosen in this study) is not suitable for studying key mediators of adaptive immunity activated by sustained inflammation. For studying these mediators, other in vivo models such as tape stripping and application of leukotriene $\mathrm{B}_{4}$ would be more appropriate [3-5].

We confirm our hypothesis that histamine iontophoresis causes local and acute cutaneous inflammation with minimal barrier impairment. The minimal barrier impairment was demonstrated by the minor increase and fast recovery of TEWL and by the absence of an increased proliferative response [24]. Previous works already suggested that the effects of iontophoresis at modest current densities $\left(<0.5 \mathrm{~mA} / \mathrm{cm}^{2}\right)$ on TEWL are largely accounted for by hydration induced by the contact with the solution to be administered [25], albeit possible disorganization of the lipid bilayers in the SC cannot be ruled out [26]. On the other hand, histology showed that this model had sec-

Fig. 5. Representative immunofluorescence photographs of expression of K16 (green) and filaggrin (red) in 2 volunteers (a-f and $\mathbf{g}-\mathbf{n}$, respectively) at baseline (a-c and $\mathbf{g - i}$ ) and at $72 \mathrm{~h}$ after histamine iontophoresis (d-f and I-n). Diamidine phenylindole was used as counterstaining (blue). In both volunteers, no expression of $\mathrm{K} 16$ can be detected at baseline (b, h) or at $72 \mathrm{~h}$ after histamine iontophoresis $(\mathbf{e}, \mathbf{m})$, whereas a slightly increased intensity in the filaggrin signal is visible at $72 \mathrm{~h}(\mathbf{f}, \mathbf{n})$ compared to control skin (c, i). The last row $(\mathbf{o}, \mathbf{p}, \mathbf{q})$ shows an example of psoriatic skin, used as positive control for the increased suprabasal expression of K16 (p) and as negative control for the absence of filaggrin expression (q) compared to normal skin.

Skin Responses to Histamine ondary effects in the epidermal compartment, since a slight yet significant increase in epidermal thickness was present at $72 \mathrm{~h}$. In the absence of an increased proliferative response, the thicker epidermis might be partly attributed to an effect on late-differentiation markers like filaggrin. Iontophoresis was previously shown to induce the loss of the epidermal calcium gradient, and in turn the loss of the epidermal calcium gradient has been shown to decrease differentiation-specific markers $[27,28]$. In in vitro experiments on human keratinocytes it was observed that the addition of histamine reduced the expression of differentiation-specific proteins [29]. The slightly higher expression of filaggrin observed at 24 and $72 \mathrm{~h}$ might thus be a reaction to a transient decrease caused by either iontophoresis or histamine or by the 2 combined. Another possible explanation might be that the spongiosis elicited by the acute histamine reaction, together with an intact skin barrier limiting free movement of water, could have induced an imbalance in the water transport at the interface between the living epidermis and the SC; hence, the higher intercellular spaces visible in the HE images (Fig. 3). The increase in epidermal thickness at 24 and $72 \mathrm{~h}$ might in turn be responsible for the change in the $\mathrm{a}^{*}$ value measured at these time points.

The secondary objective of this study was to explore whether skin responses to histamine iontophoresis differ significantly between SS and NSS subjects. The only significant difference was a higher VAS score for itch at 30 min after stimulation. The occurrence of increased sensory perceptions in SS is in agreement with the results reported by previous clinical studies [18-20], and it has been recognized by the International Forum for the Study of Itch, which has recently initiated a special interest group on SS [30]. On the other hand, in contrast to the aberrant vascular reactions in SS reported previously [20], we could not detect differences in skin redness measured by the $\mathrm{a}^{*}$ value or in the extent of the wheal-andflare reaction measured by image analysis. One reason could be due to the low number of volunteers included in each group, preventing to identify subtle differences between SS and NSS subjects. Another reason could be due to insufficient sensitivity and specificity of the measurements used. The $\mathrm{a}^{*}$ value is difficult to interpret in this model, since it is known to be influenced by several factors, among which edema [31], blood volume, and vasodilation [32], all variables affected by histamine. To get more insights into the vascular reactions, additional parameters could be evaluated, for example the reflectance spectra from the skin [32], the extent and topographical map of the wheal [33], and the changes in concentration/

Skin Pharmacol Physiol 2017;30:246-259 DOI: 10.1159/000477416 
velocity of erythrocytes [34]. The lack of differences in VAS score for itch during topical histamine application on the buttock and on the volar forearm does not support a major impairment of the skin barrier in SS, contrary to other conditions (e.g., atopic dermatitis, dandruff) in which topical histamine was shown to elicit an itchy response [7, 21]. However, the higher baseline TEWL and the trend to higher VAS score reported by SS subjects during topical histamine application on the volar forearm suggest subtle aberrant properties of the SC, which should be evaluated with more sensitive and specific approaches [35].

In conclusion, we propose that histamine iontophoresis can be used as in vivo model to elicit local and acute skin inflammation with minimal impact on the skin barrier, in contrast to tape stripping and topical application of irritants in which the skin barrier is disrupted either mechanically or chemically. In particular, this model could be applied to skin disorders in which aberrant cutaneous mast cells and their mediators play a role, for example, to investigate the still poorly defined pathomechanisms underlying chronic spontaneous urticaria [36] or to help the diagnosis of different variants of mastocytosis [37]. The effect of the model on mast cell dynamics could be analyzed directly in skin biopsies; otherwise, mast cell degranulation could be indirectly assessed by microdialysis and subsequent histamine measurement [38]. Concomitant biophysical measurements can be added to assess the effects of the model at the (sub)clinical scale. Of note, the status of the barrier function should be assessed before application of the model, to control whether abnormal skin reactions should be related to aberrant barrier properties rather than to different mast cell dynamics
[7]. Should differential responses compared to controls emerge, further clinical trials could employ the histamine iontophoresis model also to monitor disease activity and the response to treatments. With respect to the evaluation of aberrant vascular reactions in sensitive skin, future studies using histamine iontophoresis should include a higher number of volunteers and evaluate the wheal-andflare reaction with sensitive and specific approaches [3234].

\section{Acknowledgments}

The costs incurred by this study were paid by Philips Electronics Nederland BV. Natallia Uzunbajakava is an employee of Philips Electronics Nederland BV and received a salary for this study. This study was performed according to the Investigation Agreement between Philips Electronics Nederland BV, acting through Philips Research ("Philips"), and Radboudumc Dermatologie BV ("Institution"). Philips acts as the sponsor of the Investigation and funds the work by reimbursing the Institution for all documented costs made during the study (incl. the salary of Denise Falcone), in accordance with the cost estimates and up to the yearly maximum amounts.

\section{Statement of Ethics}

The study was approved by the ethics committee Regio Arnhem-Nijmegen.

\section{Disclosure Statement}

The authors declare that they have no conflict of interest.

\section{References}

1 van Smeden J, Janssens M, Gooris GS, Bouwstra JA: The important role of stratum corneum lipids for the cutaneous barrier function. Biochim Biophys Acta 2014;1841:295313.

2 Fluhr JW, Darlenski R, Angelova-Fischer I, Tsankov N, Basketter D: Skin irritation and sensitization: mechanisms and new approaches for risk assessment. 1. Skin irritation. Skin Pharmacol Physiol 2008;21:124135.

3 Hendriks AG, Keijsers RR, Seyger MM, van Erp PE, van de Kerkhof PC: Are newly discovered drivers of immune-mediated skin disorders expressed in normal skin regenerating from standardized surface injury? Dermatology 2014;228:255-260.
4 Peppelman M, van den Eijnde WA, Jaspers EJ, Gerritsen MJ, van Erp PE: Combining tape stripping and non-invasive reflectance confocal microscopy: an in vivo model to study skin damage. Skin Res Technol 2015;21:474-484.

5 Hendriks AG, Keijsers RR, Seyger MM, van de Kerkhof PC, van Erp PE: Cutaneous application of leukotriene $\mathrm{B}_{4}$ as an in vivo model of psoriasis-like skin inflammation: an immunohistological study. Skin Pharmacol Physiol 2014;27:120-126.

6 Darsow U, Ring J, Scharein E, Bromm B: Correlations between histamine-induced wheal, flare and itch. Arch Dermatol Res 1996;288: 436-441.
7 Heyer G, Hornstein OP, Handwerker HO: Skin reactions and itch sensation induced by epicutaneous histamine application in atopic dermatitis and controls. J Invest Dermatol 1989;93:492-496.

8 Shim WS, Tak MH, Lee MH, Kim M, Kim M, Koo JY, et al: TRPV1 mediates histamine-induced itching via the activation of phospholipase $\mathrm{A}_{2}$ and 12-lipoxygenase. J Neurosci 2007; 27:2331-2337.

9 Kalia YN, Naik A, Garrison J, Guy RH: Iontophoretic drug delivery. Adv Drug Deliv Rev 2004;56:619-658.

10 Sieg A, Wascotte V: Diagnostic and therapeutic applications of iontophoresis. J Drug Target 2009;17:690-700.
Falcone/Uzunbajakava/Richters/ van de Kerkhof/van Erp 
11 van Laarhoven AI, Kraaimaat FW, WilderSmith OH, van Riel PL, van de Kerkhof PC, Evers AW: Sensitivity to itch and pain in patients with psoriasis and rheumatoid arthritis. Exp Dermatol 2013;22:530-534.

12 van Laarhoven AI, Walker AL, Wilder-Smith $\mathrm{OH}$, Kroeze S, van Riel PL, van de Kerkhof P, et al: Role of induced negative and positive emotions in sensitivity to itch and pain in women. Br J Dermatol 2012;167:262-269.

13 Yosipovitch G, Fast K, Bernhard JD: Noxious heat and scratching decrease histamine-induced itch and skin blood flow. J Invest Dermatol 2005; 125:1268-1272.

14 Magerl W, Westerman RA, Mohner B, Handwerker HO: Properties of transdermal histamine iontophoresis: differential effects of season, gender, and body region. J Invest Dermatol 1990;94:347-352.

15 Richters R, Falcone D, Uzunbajakava N, Verkruysse W, van Erp P, van de Kerkhof P: What is sensitive skin? A systematic literature review of objective measurements. Skin Pharmacol Physiol 2015;28:75-83.

16 Stander S: Sensitive skin - a global challenge with upcoming solutions. J Eur Acad Dermatol Venereol 2016;30 (suppl 1):1.

17 Richters R, Uzunbajakava N, Hendriks J, Bikker J-W, van Erp P, van de Kerkhof P: A model for perception-based identification of sensitive skin. J Eur Acad Dermatol Venereol 2017;31:267-273.

18 Richters R, Hendriks J, Uzunbajakava N, Janssen L, Falcone D, van Erp P, et al: Responses to sodium dodecyl sulphate as an in vivo human model to study the pathomechanisms underlying sensitive skin. Exp Dermatol 2016;25:407-409.

19 Richters R, Hoogedoorn L, Uzunbajakava N, Janssen L, Nuijs T, van Erp P, et al: Clinical, biophysical, immunohistochemical, and in vivo reflectance confocal microscopy evaluation of the response of subjects with sensitive skin to home-use fractional non-ablative photothermolysis device. Lasers Surg Med 2016; 48:474-482.
20 Richters R, Uzunbajakava N, Falcone D, Hendriks J, Jaspers E, van de Kerkhof P, et al: Clinical, biophysical and immunohistochemical analysis of skin reactions to acute skin barrier disruption - a comparative trial between participants with sensitive skin and those with nonsensitive skin. Br J Dermatol 2016;174: 1126-1133.

21 Harding CR, Moore AE, Rogers JS, Meldrum $\mathrm{H}$, Scott AE, McGlone FP: Dandruff: a condition characterized by decreased levels of intercellular lipids in scalp stratum corneum and impaired barrier function. Arch Dermatol Res 2002;294:221-230.

22 Ridler TW, Calvard S: Picture thresholding using an iterative selection method. IEEE Trans Syst Man Cybern 1978;8:630-632.

23 Kulka M, Sheen CH, Tancowny BP, Grammer LC, Schleimer RP: Neuropeptides activate human mast cell degranulation and chemokine production. Immunology 2008;123:398-410.

24 Choi EH, Kim MJ, Yeh BI, Ahn SK, Lee SH Iontophoresis and sonophoresis stimulate epidermal cytokine expression at energies that do not provoke a barrier abnormality: lamellar body secretion and cytokine expression are linked to altered epidermal calcium levels. J Invest Dermatol 2003;121:1138-1144.

25 Curdy C, Kalia YN, Guy RH: Non-invasive assessment of the effects of iontophoresis on human skin in vivo. J Pharm Pharmacol 2001; 53:769-777.

26 Jadoul A, Bouwstra J, Préat VV: Effects of iontophoresis and electroporation on the stratum corneum. Review of the biophysical studies. Adv Drug Deliv Rev 1999;35:89-105.

27 Elias PM, Ahn SK, Denda M, Brown BE, Crumrine D, Kimutai LK, et al: Modulations in epidermal calcium regulate the expression of differentiation-specific markers. J Invest Dermatol 2002;119:1128-1136.

28 Lee SH, Choi EH, Feingold KR, Jiang S, Ahn SK: Iontophoresis itself on hairless mouse skin induces the loss of the epidermal calcium gradient without skin barrier impairment. J Invest Dermatol 1998;111:39-43.
29 Gschwandtner M, Mildner M, Mlitz V, Gruber F, Eckhart L, Werfel T, et al: Histamine suppresses epidermal keratinocyte differentiation and impairs skin barrier function in a human skin model. Allergy 2013;68:3747.

30 Misery L, Stander S, Szepietowski JC, Reich A, Wallengren J, Evers AW, et al: Definition of sensitive skin: an expert position paper from the Special Interest Group on Sensitive Skin of the International Forum for the Study of Itch. Acta Derm Venereol 2017;97:4-6.

31 Piérard GE: EEMCO guidance for the assessment of skin colour. J Eur Acad Dermatol Venereol 1998;10:1-11.

32 Verkruysse W, Lucassen GW, van Gemert MJ: Simulation of color of port wine stain skin and its dependence on skin variables. Lasers Surg Med 1999;25:131-139.

33 dos Santos RV, Mlynek A, Lima HC, Martus P, Maurer M: Beyond flat wheals: validation of a three-dimensional imaging technology that will improve skin allergy research. Clin Exp Dermatol 2008;33:772-775.

34 Henricson J, Nilsson A, Tesselaar E, Nilsson G, Sjöberg F: Tissue viability imaging: microvascular response to vasoactive drugs induced by iontophoresis. Microvasc Res 2009;78: 199-205.

35 Richters R, Falcone D, Uzunbajakava N, Varghese B, Caspers P, Puppels GJ, et al: Sensitive skin: assessment of the skin barrier using confocal Raman micro-spectroscopy. Skin Pharmacol Physiol 2017;30:1-12.

36 Metz M, Krull C, Maurer M: Histamine, TNF, C5a, IL-6, -9, -18, -31, -33, TSLP, neopterin, and VEGF are not elevated in chronic spontaneous urticaria. J Dermatol Sci 2013;70: 222-225.

37 Gulen T, Hagglund H, Dahlen B, Nilsson G: Mastocytosis: the puzzling clinical spectrum and challenging diagnostic aspects of an enigmatic disease. J Intern Med 2016;279:211228.

38 Petersen LJ, Church MK, Stahl Skov P: Histamine is released in the wheal but not the flare following challenge of human skin in vivo: a microdialysis study. Clin Exp Allergy 1997; 27:284-295. 